\title{
An Analysis of the Strayton Engine, a Brayton and Stirling Cycle Recuperating Engine
}

\author{
Jeffryes W. Chapman*, Donald L. Simon ${ }^{\dagger}$, and Ezra O. McNichols ${ }^{\ddagger}$ \\ NASA Glenn Research Center, Cleveland, $\mathrm{OH}, 44135$, USA
}

\begin{abstract}
This paper explores the novel Strayton engine concept. This engine combines the cycles of a Brayton engine with that of a Stirling engine to create a highly efficient recuperating gas turbine engine. In the explored case, both Brayton cycle and Stirling cycle engines are used to generate electrical power. Additionally, the Stirling engine is used to draw heat out of the Brayton turbine (acting to cool the turbine blades), while also pumping heat into Brayton cycle just before combustion occurs (acting as the mechanism for recuperation). The purpose of this paper is to detail the system level modeling techniques used to generate the simulation, perform a cycle analysis of the combined cycle engine, identify key technologies and challenges associated with the concept, and compare potential performance gains with existing gas turbine engines and internal combustion engines. Topics such as controls, blade cooling effects, engine weight, and heat transfer using heat pipe are also explored. Results from this work show potential architectures that could provide the required heat transfer rates, potential control strategies, and performance benefits, including efficiency gains between $10 \%$ and $3 \%$ on engines ranging from $200 \mathrm{HP}$ to $670 \mathrm{HP}$ with the combined cycle engine.
\end{abstract}

\section{Nomenclature}

$\begin{array}{ll}\text { Alt } & \text { Altitude } \\ \text { ARMD } & \text { Aeronautics Research Directorate } \\ \text { Eff } & \text { Efficiency } \\ \text { IC } & \text { Internal combustion } \\ \text { LPC } & \text { Low pressure compressor } \\ \text { LPT } & \text { Low pressure turbine } \\ \text { NPSS } & \text { Numerical Propulsion System Simulation } \\ \text { OHP } & \text { Oscillating heat pipes } \\ \text { OPR } & \text { Overall pressure ratio } \\ \text { P } & \text { Pressure } \\ \text { S } & \text { Entropy } \\ \text { SFC } & \text { Specific fuel consumption } \\ \text { Q } & \text { Heat transfer } \\ \dot{Q} & \text { Heat transfer rate or power } \\ \text { SEA } & \text { Stirling Engine Analysis } \\ \text { T } & \text { Temperature } \\ \mathrm{T}_{4} & \text { Temperature at station } 4 \text { (turbine inlet temperature) } \\ \mathrm{T}_{7} & \text { Temperature at station } 7 \text { (nozzle input temperature) } \\ \text { V } & \text { Volume } \\ \text { VTOL } & \text { Vertical Takeoff and Landing } \\ \text { W } & \text { Work } \\ \dot{\mathrm{W}} & \text { Work rate or power }\end{array}$

\footnotetext{
* Research Engineer, 21000 Brookpark Rd., Cleveland OH, MS-5-11.

${ }^{\dagger}$ Research Engineer, 21000 Brookpark Rd., Cleveland OH, MS-5-11.

‡ Research Engineer, 21000 Brookpark Rd., Cleveland OH, MS-77-1.
} 


\section{Subscripts}

$\begin{array}{ll}\text { C } & \text { Cold } \\ \text { H } & \text { Hot } \\ \text { hp } & \text { heat pipe } \\ \text { st } & \text { Stirling engine } \\ \text { W } & \text { Work }\end{array}$

\section{Introduction}

$\mathrm{I}_{\mathrm{in}}^{\mathrm{n}}$

trest in Electrified Aircraft Propulsion (EAP) research for vertical takeoff and landing (VTOL) aircraft has been

increasing as understanding of the potential benefits in performance, efficiency, emissions, noise levels, and system cost are shown.[1,2] To gain a better understanding of the challenges of the new platform and design space, NASA's Revolutionary Vertical Lift Technologies (RVLT) project under the Aeronautics Research Directorate (ARMD) has invested in developing a number of concept vehicles that utilize EAP systems that represent the critical technologies for the applicable platforms. Examples include the quad-copter, multi-rotor, coaxial helicopter, tiltwing, and lift + cruise.[3, 4] Operational power for each of these vehicles is supplied from batteries, gas turbine engines, or a combination of the two. It may also be noticed that the vehicles considered by the RVLT project generally have a fairly low power requirement, with the lift + cruise concept requiring under $1500 \mathrm{HP}$. Powering EAP vehicles requires a power source that is reliable, efficient, and maintains a high specific power. For this purpose there are two main options to consider, batteries and a hydrocarbon burning engine. Currently, the energy density of hydrocarbons is much greater than that of batteries (around $0.6 \mathrm{MJ} / \mathrm{kg}$ for batteries and $5.9 \mathrm{MJ} / \mathrm{kg}$ for jet fuel),[5] and gas turbine technology maintains a track record of safe and efficient power generation, therefore an engine is a practical option. The Strayton engine concept, being described within this paper, is a hydrocarbon based solution that is a potential match for this type of mission. This paper details cycle, thermal transfer, and control analysis for this advanced engine concept. Additionally, it lays out the critical technologies and challenges for system development moving forward.

The Strayton engine is a combined Brayton and Stirling cycle engines. The Brayton cycle engine is a constant pressure heat engine, with ideal P-V (pressure to volume) and T-S (temperature to entropy) diagrams shown in Figure 1. The ideal cycle operates by first performing an isentropic compression on a gas (1-2). Second, heat is added to the system, commonly by some sort of combustion with no loss in pressure (2-3). Third, an isentropic decompression occurs where energy can be taken from the system as work (3-4). Typically, this energy is used to run the compression process with the remainder output for a desired purpose. Finally, additional waste heat is rejected (4-1). Work output by the Brayton cycle engine can be used to generate thrust via the hot exhaust gas, or to drive machinery via a rotating shaft. Brayton cycle engines are fairly common today and can be used as aircraft propulsion (jet engine), to drive large ships, or to simply generate electricity. The Stirling cycle engine is a closed cycle oscillating heat engine that utilizes constant temperature expansion. The ideal P-V and T-S diagrams are shown in Figure 2. The ideal Stirling operates by first performing an isothermal volume expansion making use of an external heat source (1-2). Second, a constant volume heat transfer occurs to heat up a regenerator (2-3). Third, an isothermal compression occurs with waste heat rejected to an external cold source (3-4). Finally, another constant volume heat transfer occurs to cool the regenerator (4-1). Work output from a Stirling engine is gathered from an oscillating piston that moves axially with the compression cycle. Applications for Stirling engines aren't quite as common as Brayton cycle engine, but they have been used for cryocoolers, power generation, naval submarine, and they have even been considered for space based applications.[6, 7] 

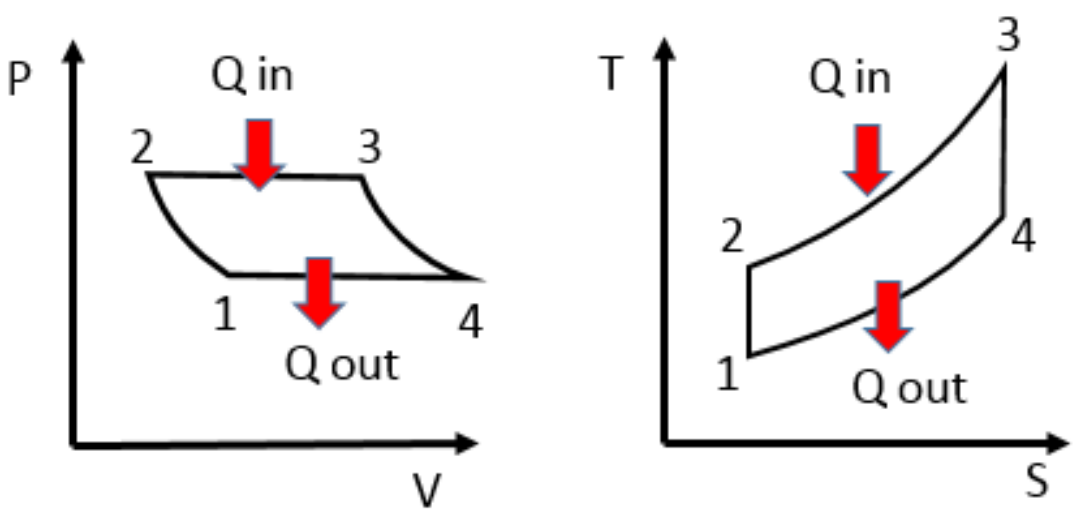

Figure 1. Brayton cycle P-V and T-S diagrams.
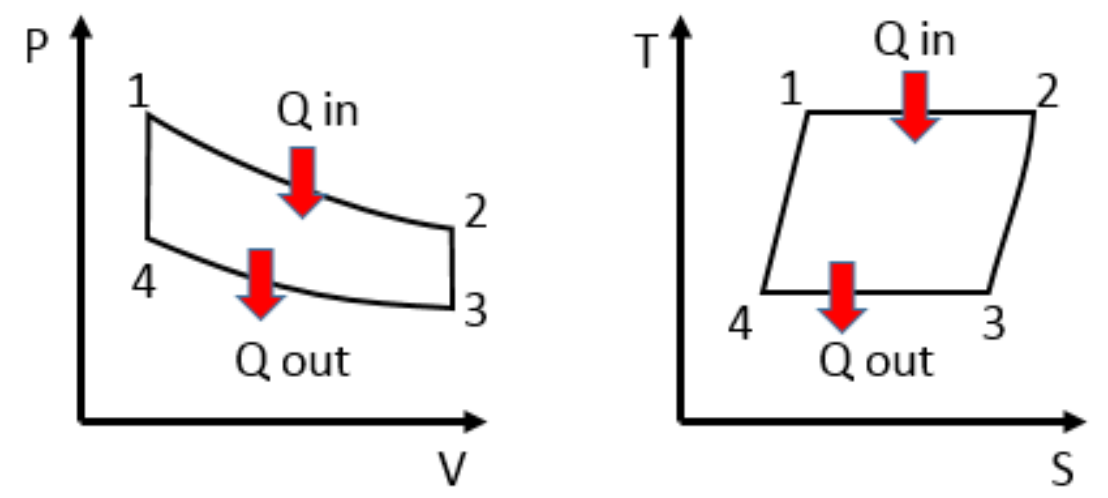

Figure 2. Stirling cycle P-V and T-S diagrams.

In the Strayton engine concept, the Brayton and Stirling cycles operate in synergy, with the Stirling acting as a recuperator for the Brayton cycle and the Brayton acting to power the Stirling. Preliminary study and development of this concept were carried out by Rodger Dyson of NASA.[8] The architecture of this engine consists of a gas turbine engine, with a Stirling engine replacing the engine shaft. Heat transfer rate, $\dot{\mathrm{Q}}_{\mathrm{H}}$, is drawn down through the turbine blades and used to power the Stirling engine. Wasted thermal power, $\dot{\mathrm{Q}}_{\mathrm{C}}$, from the Stirling is then introduced to the gas turbine system using a heat exchanger directly before engine combustion, as shown in Figure 3 . This architecture has two main advantages. First, pulling heat down through the turbine blades would have a cooling effect on the structure allowing the system to reduce or remove blade cooling flow. Second, Stirling waste heat could be used to create a recuperation cycle with the gas turbine, increasing overall efficiency. Power from the system would be delivered via two mechanisms, a shaft rotation and a separate oscillating internal shaft. In this study it was assumed all power would be generated with a dual axis generator and delivered as electrical power. The initial study of this concept showed promising increases in overall efficiency (between 28\% and 38\%) over a typical non-recuperating gas turbine with an efficiency of $29 \%$ as shown in Ref. (8). This paper will offer another look at these efficiency gains adding fidelity in the gas turbine engine model and a heat transfer mechanism. 


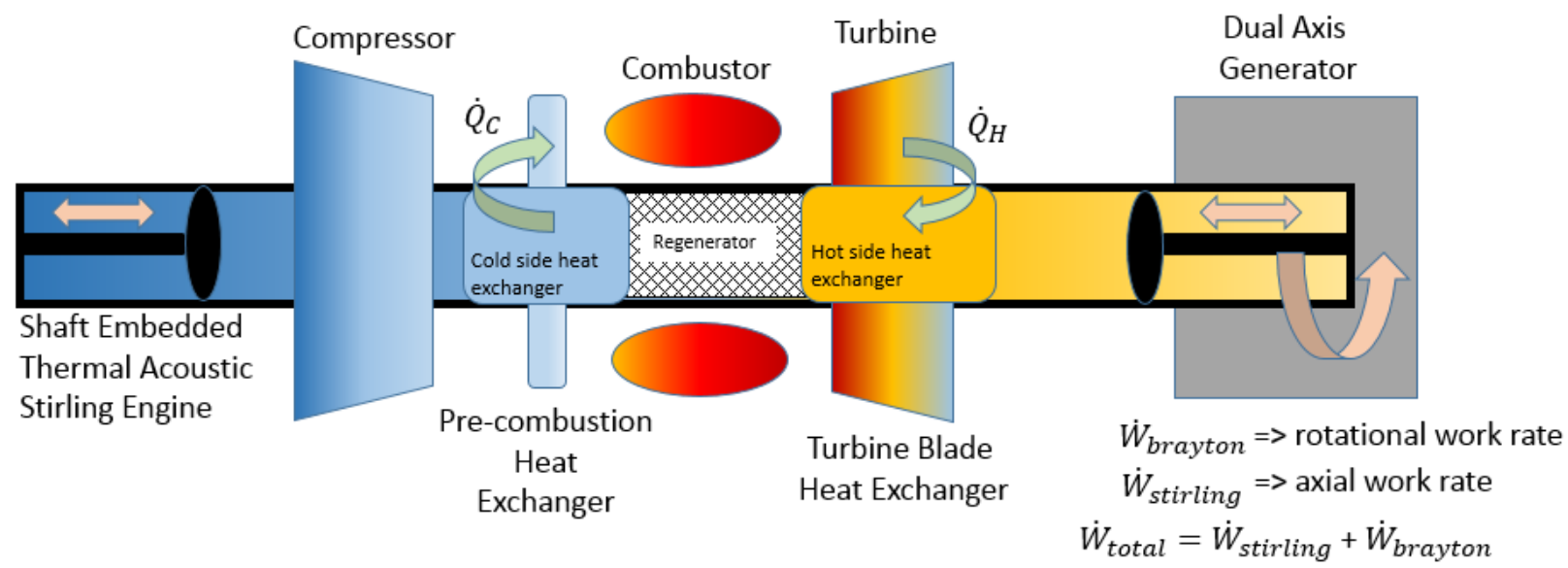

Figure 3. Diagram of Strayton Engine.

The architecture of the Strayton engine was assumed to be a single spool with a one stage radial compressor (or one stage axial and one stage radial) and a two stage axial turbine. To reduce cost and weight it was also assumed that the dual axis generator was connected directly to the single shaft. The considered Stirling engine was a one stage thermal acoustic engine. This Stirling acts to amplify incoming power by roughly 1:3, therefore if $1 \mathrm{HP}$ is input to oscillate the Stirling cold end piston, 3 HP would be harnessed from the resulting oscillation of the Stirling hot end piston. Acoustic waves are generated on the cold end via a short axial moving shaft, which then activates the shaft on the hot end (also axial). The model developed for the cycle performance study was created using the software package Numerical Propulsion System Simulation (NPSS). [9] This modular software package contains a suite of components that may be connected together to create a 0-D energy based gas turbine engine model as well as all the capabilities to perform the heat transfer. Cycle studies utilized a simplified Stirling engine model that assumed efficiency was equal to $50 \%$ of the Carnot efficiency as shown in Eq. ( 1 ) While this assumption does not capture all the effects of the thermal acoustic engine it was deemed to be close enough at this stage of the analysis.[10] Control studies were also performed for the Stirling engine using a MATLAB-based Stirling engine cycle model created using the Ohio University Stirling Engine Analysis (SEA) code.[11]

$$
\text { Carnot Efficiency }=1-\frac{T_{C}}{T_{H}}
$$

Although this paper will look at the Strayton in terms of EAP, these technologies are general and could be applied for a wide range of purposes. These applications may include conductive turbine blade cooling, engine recuperation (as mentioned above), or general combined cycle designs for power, aeronautical, or space applications as demonstrated in literature.[12,13,14] Additionally, offering a competitive small gas turbine engine with efficiencies similar to those of larger engines would allow gas turbines to compete with internal combustion (IC) engines in the small engine marketplace.

Subsequent sections of this paper detail the engine design and optimization study. Specifically, a detailed description of the engine modeling is given in Section II. An Engine cycle analysis is detailed in Section III, followed by a study of the control in Section IV. Section V contains a review of key system technologies and challenges and, finally, conclusions are given in Section VI.

\section{Engine Modeling}

The engine model was created with NPSS and consists of a single spool engine with a single stage radial compressor (or a single axial compressor followed by a single radial compressor) and a two stage turbine. The two engine models were connected via two steady-state heat flow models: a cold side compressor exit heat flow model and hot side turbine heat flow model. Both of these heat flow models took into account convection via core stream and heat pipe convection leading to the Stirling engine. A station diagram of model components is shown in Figure 4, where 
$\dot{\mathrm{Q}}_{\mathrm{c}}$ is heat transfer rate out from the Stirling cold side, $\dot{\mathrm{Q}}_{\mathrm{H}}$ is heat transfer rate moving into the Stirling hot side, $\dot{\mathrm{W}}_{\text {stirling }}$ is the work rate by the Stirling, $\dot{\mathrm{W}}_{\text {brayton }}$ is work rate done by the gas turbine, LPC is the low pressure compressor, and LPT is the low pressure turbine.

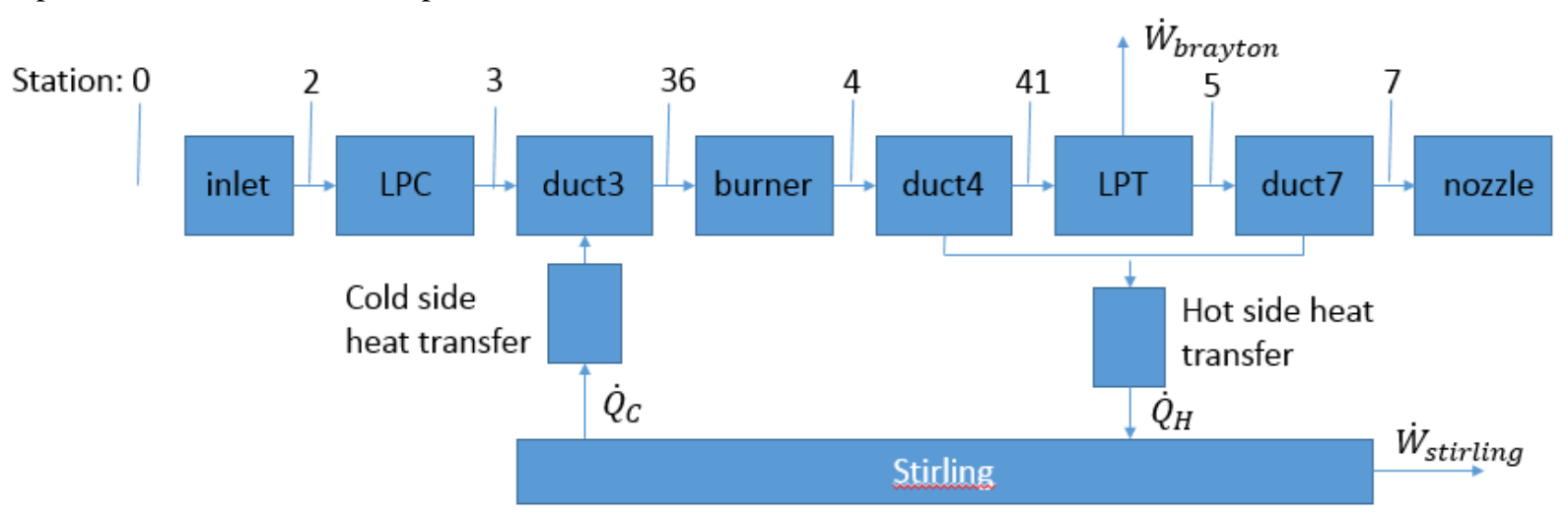

Figure 4. Block diagram of Strayton NPSS model.

Power transfer between the two models was translated through NPSS duct components. The heat transfer rate from the cold side of the Stirling was delivered to duct3 directly after the LPC through an assumed heat exchanger, and heat transfer rate for the hot side of the Stirling was drawn from duct4 and duct7 as an approximation for turbine blade conduction. Brayton flow temperatures, used as a starting point for the heat transfer model, were assumed to be $\mathrm{T}_{3}$ on the cold side and the average of $\mathrm{T}_{4}$ and $\mathrm{T}_{7}$ on the hot side.

Estimation of Brayton cycle engine component performance was based on generic component maps that are scaled to meet engine power requirements. Compressor efficiency was adjusted to meet polytrophic efficiencies typical for the compressor size, and was determined based on empirical correlations relating polytropic efficiency to compressor corrected core flow or core size[15]. Brayton cycle engine weight was also determined with an empirical correlation relating engine dry weight to total engine inlet flow rate (at maximum power sea level static conditions).[15] This weight was then adjusted to include a Stirling weight estimate where power was correlated with weight at $0.6 \mathrm{HP} / \mathrm{lbm}$.

In modeling the heat transfer, a lumped mass heat transfer model was developed to relate the operating temperatures, pressures, velocities, and rough dimensions of blades to the heat transfer coefficients. The diagram in Figure 5 shows the energy balance and geometric layout. Heat is transferred from the hot gas in the turbine to the turbine blade, which is then transferred to a heat pipe embedded in the blade and then to the hot side of the Stirling engine. The remaining heat, after power extraction, is rejected on the cold side of the Stirling through heat pipes to the compressor exit, to heat the air before entering the combustor.

For this analysis, it was assumed heat would be transferred between the Stirling and the blades, or duct, by using oscillating heat pipes (OHP). The OHP can be replaced with traditional heat pipes in the stators, or any other stationary part. Changing the type of heat pipe would change some of the equations in the analysis, but the results would only slightly change since their thermal characteristics are similar. A Python code was developed to solve the heat transfer equations. The code allows for all air properties in both the compressor exit and turbine inlet to be temperature and pressure dependent.

The heat transfer coefficients used for the external surface of the vanes was approximated using the correlation for turbulent flow over a flat plate [16]. Heat transfer coefficients for the internal heat pipes were approximated to be 880 $\mathrm{Btu} / \mathrm{hr} / \mathrm{ft}^{2} /{ }^{\circ} \mathrm{R}$, which is a low estimate for these devices since heat is not only transferred through forced convection but also from boiling. 


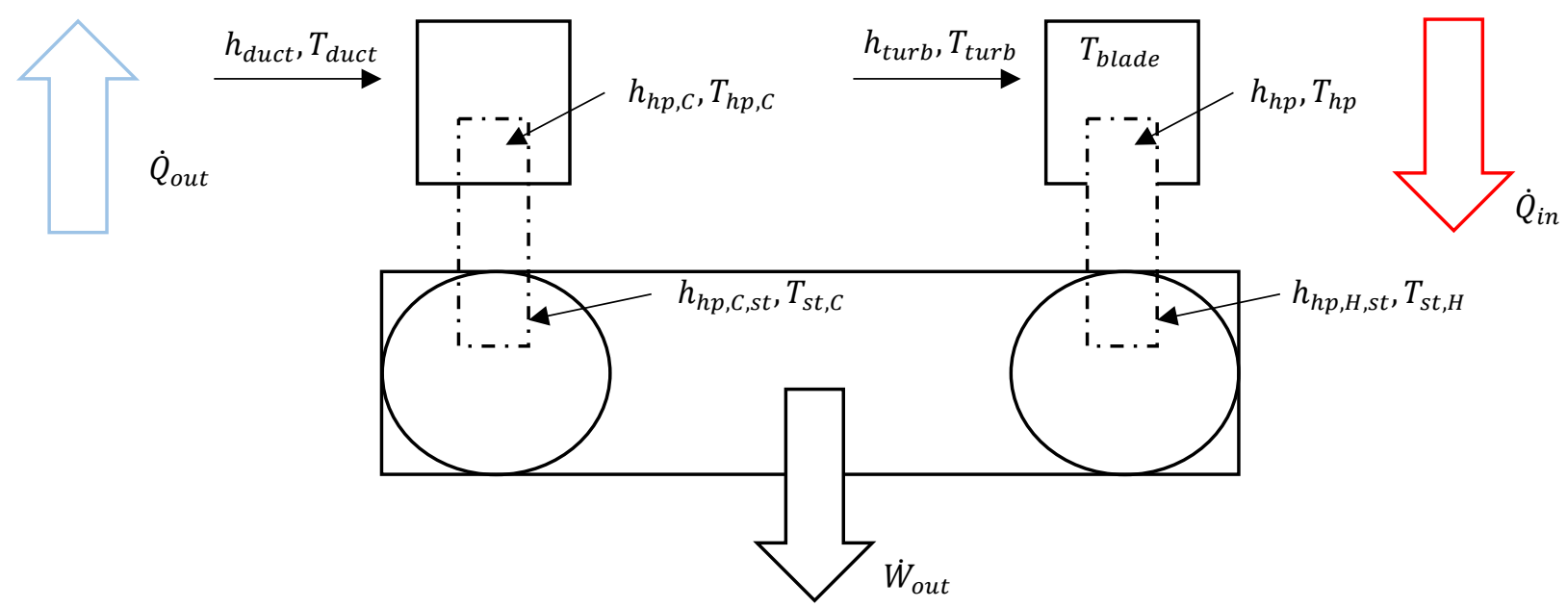

Figure 5. Energy Balance on Strayton Concept.

\section{Cycle Analysis Results}

Results for this project are summarized into two main studies, a sensitivity of design criteria study and a control study. The purpose of the sensitivity study is to determine peak efficiency for the given power points, in this case $200 \mathrm{HP}(150 \mathrm{~kW})$ and $670 \mathrm{HP}(500 \mathrm{~kW})$. The purpose of the control study is to examine the control modes of the Brayton and Stirling cycles, and to schedule the operation of these two cycles in a coordinated fashion to achieve optimal efficiency during off-design operation. For comparison purposes a Brayton cycle only engine was simulated at the same power point as the Strayton engine. In this baseline engine, $T_{4}$ is used directly for blade temperature. For the Strayton, $\mathrm{T}_{4}$ is assumed to be the liner temperature. In the Strayton, worst case blade temperature is then calculated based on the steady-state heat transfer model utilizing $\mathrm{T}_{4}$ as the hot side core flow temperature.

Three main design parameters are analyzed for the sensitivity study: maximum blade temperature, overall pressure ratio, and hot side heat transfer rate to the Stirling. A comparison of Strayton and Brayton efficiency based on blade temperature at the 200HP power point can be seen in Figure 4. Looking at this figure, it can be seen that Strayton efficiency rises faster than the baseline Brayton efficiency as blade temperature rises. This is because not only is the engine getting the efficiency advantage from the Brayton cycle, but it is also gaining efficiency and power from higher temperature ratios in the Stirling, and recuperating larger amounts of heat back into the Brayton cycle. Traces of overall pressure ratio (OPR) across the compressor and thermal efficiency sensitivity are shown in Figure 5. In this case, it can be seen that efficiencies rise with increasing pressure ratio, however, the relative rise in Strayton efficiency is less than that of the Brayton only cycle. This is because, $T_{3}$ and the temperature on the cold side of the Stirling increase, reducing Stirling temperature ratio and efficiency, as the pressure ratio increases. Additionally, compressor core size decreases due to the higher required pressure ratios at similar core flows, reducing the possible efficiency of the compressor design. These two observations show that most of the benefit gains for the cycle come with higher burner exit temperatures and not from higher overall pressure ratio increases.

Traces of Strayton efficiency and Stirling power versus hot side heat transfer rate $\left(\dot{\mathrm{Q}}_{\mathrm{H}}\right)$ are shown in Figure 6. Looking at the plots, it can be seen that the power output of the Stirling initially rises as heat transfer rate increases, but then falls as the heat transfer rate inflection point is reached. This decrease occurs because the increase in heat transfer rate into the hot section of the Stirling also increases the temperature gradient across the turbine heat circuit, resulting in lower temperatures on the hot side of the Stirling. This reduction in temperature along with rising temperature on the cold side (for the same reason) result in a lower Stirling temperature ratio and efficiency. Once the inflection point is reached, increasing heat transfer rate into the hot side section of the Stirling does not increase power output and a maximum Stirling power (34 HP at $140 \mathrm{Btu} / \mathrm{s}$ ) is reached. Overall Strayton efficiency follows a similar path, with a maximum Strayton efficiency of $33 \%$ is met at $180 \mathrm{Btu} / \mathrm{s}$, which is after the maximum Stirling power is met. For this design, a maximum $\dot{\mathrm{Q}}_{\mathrm{H}}$ was limited to $165 \mathrm{Btu} / \mathrm{s}$ because higher heat transfer levels resulted in a Stirling temperature ratio of less than 1.4 (For this study a temperature ratio of greater than 1.4 was selected as a design requirement for Stirling Engines). At the 165 Btu/s setting, Strayton efficiency is approximately 32.7\% and 
the Stirling power output is $33.2 \mathrm{HP}$. Results for the $670 \mathrm{HP}$ example were similar, however Stirling power could not be increased significantly (due to identical temperature limits), so system efficiency gains were reduced.

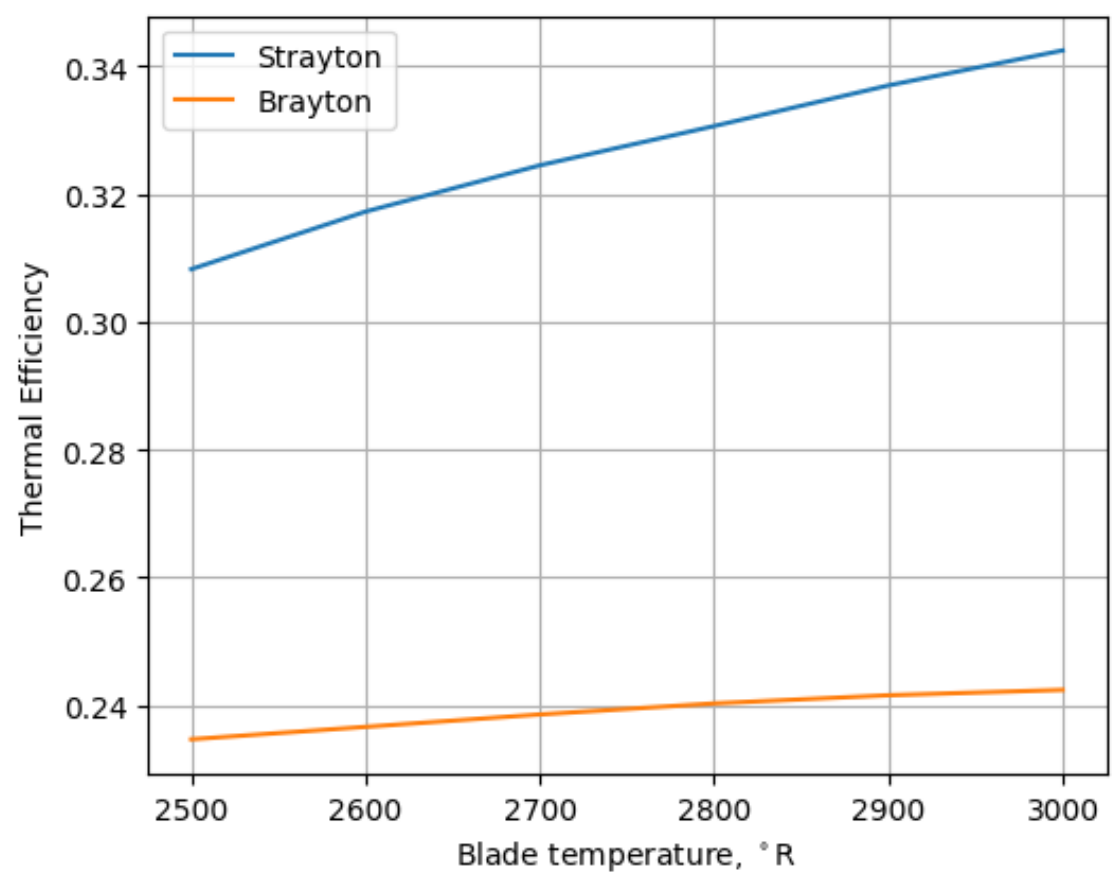

Figure 6: Brayton and Strayton efficiency vs. blade temperature, at $200 \mathrm{HP}$ power point with constant pressure ratio (6.5) and $\dot{Q}_{\mathrm{H}}(165 \mathrm{Btu} / \mathrm{s})$.

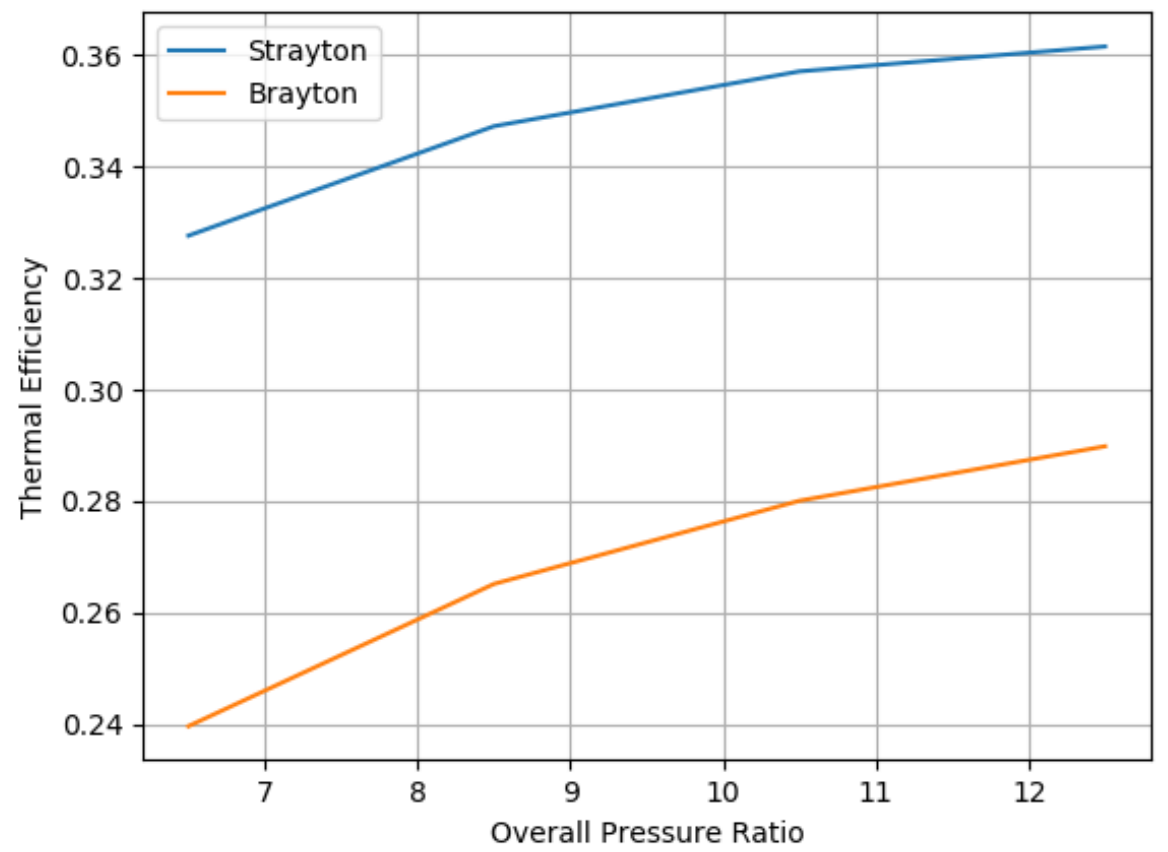

Figure 7: Brayton and Strayton efficiency vs. overall pressure ratio, at $200 \mathrm{HP}$ power point with constant blade temperature $\left(2750{ }^{\circ} \mathrm{R}\right)$ and $\dot{\mathrm{Q}}_{\mathrm{H}}(165 \mathrm{Btu} / \mathrm{s})$.

American Institute of Aeronautics and Astronautics 

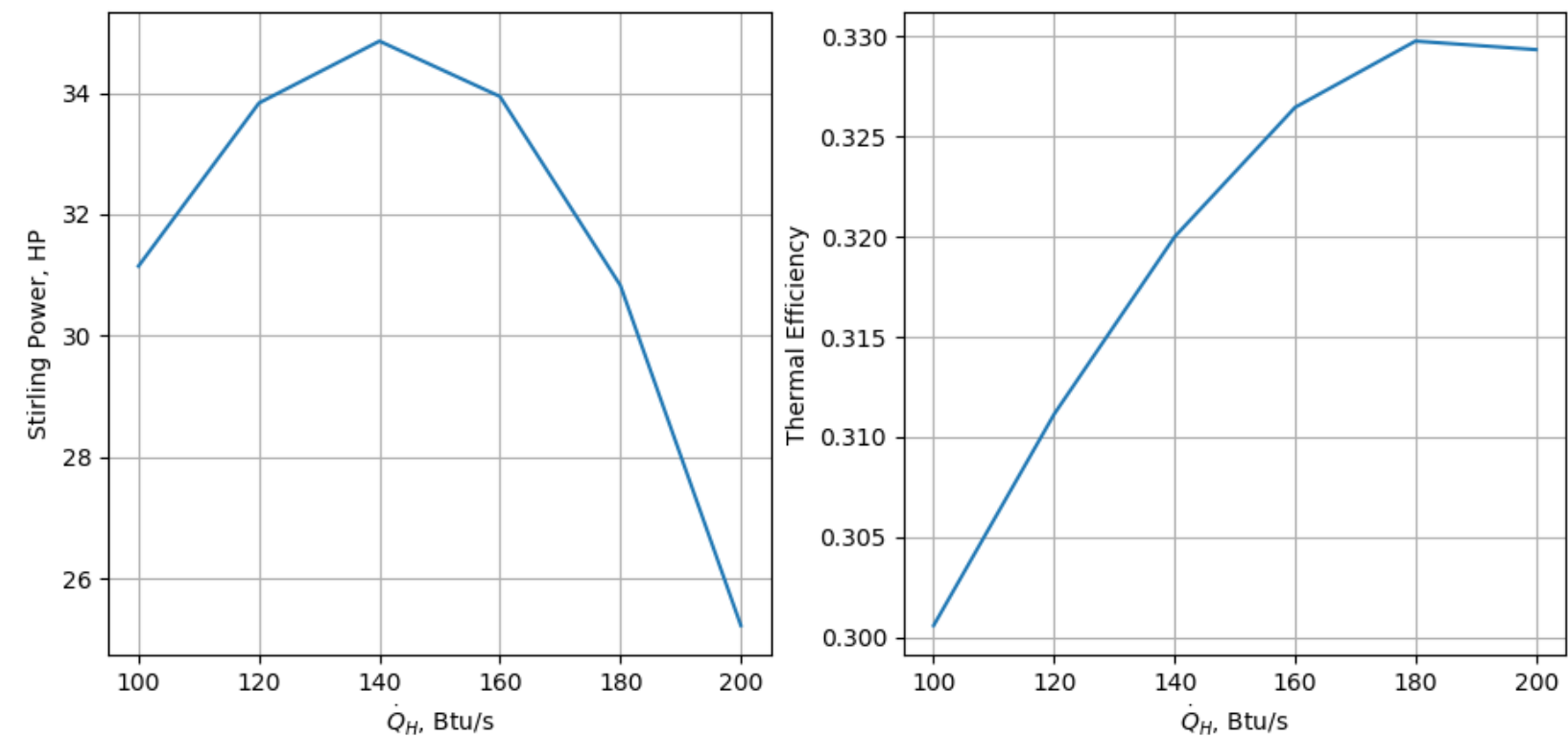

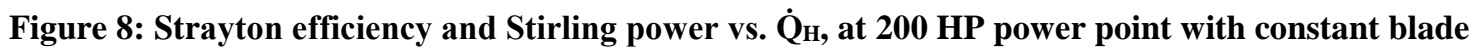
temperature $\left(2750{ }^{\circ} \mathrm{R}\right)$ and overall pressure ratio (6.5).

In this study four test engines were designed for comparison purposes: baseline Brayton cycle and Strayton engine designed at the power points of 200HP and 670HP, as mentioned above. Design criteria for each engine were set at sea level static conditions, with baseline pressure ratios of 6.5 for the $200 \mathrm{HP}$ engine(single stage radial compressor) and 10 for the $670 \mathrm{HP}$ engine(single stage radial compressor preceded by a single stage of axial compression), $3200^{\circ} \mathrm{R}$ maximum combustor liner temperature, and $2750^{\circ} \mathrm{R}$ maximum turbine blade temperature. Baseline Brayton cycle engine performance data are listed in Table 1 and Strayton performance data for the same powers are shown in Table 2. Efficiency for the two engines rise 0.09 and 0.03 for the $200 \mathrm{HP}$ and $670 \mathrm{HP}$ versions respectively. In each case Stirling operating temperatures remain relatively consistent resulting in fairly consistent Stirling power levels. To increase the ratio of power coming from the Stirling the OPR would need to be reduced, which would lower the Stirling cold side temperature. This however would also lower the efficiency of the Brayton cycle portion of the engine resulting in lower overall efficiency. Similarly, increasing OPR further reduces the Stirling power ratio effectively converting the engine into a Brayton cycle only engine. It is because of these tradeoffs that the efficiency rise for the $670 \mathrm{HP}$ engine are significantly lower than for the $200 \mathrm{HP}$ engine, and, as discussed above, higher efficiencies may be achieved with increases in temperature only, and it cannot be assumed that a larger Brayton cycle power generation will result in an equally large increase in Stirling cycle power generation.

Table 1: Baseline Brayton cycle engines at SLS design point with $2750{ }^{\circ} \mathbf{R}$ blade temperature.

\begin{tabular}{|c|c|c|c|c|c|c|}
\hline $\begin{array}{c}\text { Total } \\
\text { Power } \\
(\mathrm{HP})\end{array}$ & $\begin{array}{c}\text { Brayton } \\
\text { Power } \\
(\mathrm{HP})\end{array}$ & OPR & $\begin{array}{c}\mathrm{T} \text { liner } \\
\left({ }^{\circ} \mathrm{R}\right)\end{array}$ & Efficiency & $\begin{array}{c}\text { Fuel } \\
\text { Flow } \\
(\mathrm{lbm} / \mathrm{s})\end{array}$ & $\begin{array}{c}\text { Air Mass } \\
\text { Flow } \\
(\mathrm{lbm} / \mathrm{s})\end{array}$ \\
\hline 200 & 200 & 6.5 & 2750 & 0.24 & 0.032 & 1.11 \\
\hline 670 & 670 & 10 & 2750 & 0.29 & 0.087 & 3.23 \\
\hline
\end{tabular}


Table 2: Strayton cycle engines at SLS design point with $2750{ }^{\circ} \mathbf{R}$ blade temperature.

\begin{tabular}{|c|c|c|c|c|c|c|c|c|c|c|}
\hline $\begin{array}{c}\text { Total } \\
\text { Power } \\
(\mathrm{HP})\end{array}$ & $\begin{array}{c}\text { Brayton } \\
\text { Power } \\
(\mathrm{HP})\end{array}$ & $\begin{array}{c}\text { Stirling } \\
\text { Power } \\
(\mathrm{HP})\end{array}$ & OPR & $\begin{array}{c}\mathrm{T}_{\mathrm{st}, \mathrm{H}} \\
\left({ }^{\circ} \mathrm{R}\right)\end{array}$ & \begin{tabular}{c}
$\mathrm{T}_{\mathrm{st}, \mathrm{C}}\left({ }^{\circ} \mathrm{R}\right)$ \\
\hline 200
\end{tabular} & $\begin{array}{c}\mathrm{T} \text { liner } \\
\left({ }^{\circ} \mathrm{R}\right)\end{array}$ & Efficiency & $\begin{array}{c}\text { Fuel Flow } \\
(\mathrm{lbm} / \mathrm{s})\end{array}$ & $\begin{array}{c}\text { Air Mass } \\
\text { Flow } \\
(\mathrm{lbm} / \mathrm{s})\end{array}$ & $\begin{array}{c}\text { Stirling } \\
\text { Temperature } \\
\text { Ratio }\end{array}$ \\
\hline 670 & 640 & 33.38 & 6.5 & 1598 & 1141 & 3167 & 0.33 & 0.027 & 0.87 & 1.4 \\
\hline
\end{tabular}

A comparison of power specific fuel consumption and specific power for an array of gas turbine engines and IC engines (gathered from literature) can be seen in Figure 7 and Figure 8. In both plots the orange circles denote current production turbine engine data, and the blue circles denote current production IC engine data. The green squares represent the baseline Brayton cycle engines, and red triangles show the Strayton engine designs considered in this study. In comparing the baseline Brayton and Strayton design data, the SFC curves show a large $10 \%$ benefit in efficiency for the $200 \mathrm{HP}$ power point and a 3\% increase in efficiency with the $670 \mathrm{HP}$ point. In both cases it is estimated the Strayton engine will achieve near 0.40 SFC, which is similar to that of IC engines of the same class. Specific power points show that the Stirling engine can achieve weights similar to those of the Brayton cycle. In this case the $200 \mathrm{HP}$ engine is similar to that of the IC engines, however the $670 \mathrm{~kW}$ engine has roughly $3 \mathrm{x}$ the specific power of a similar IC engine.

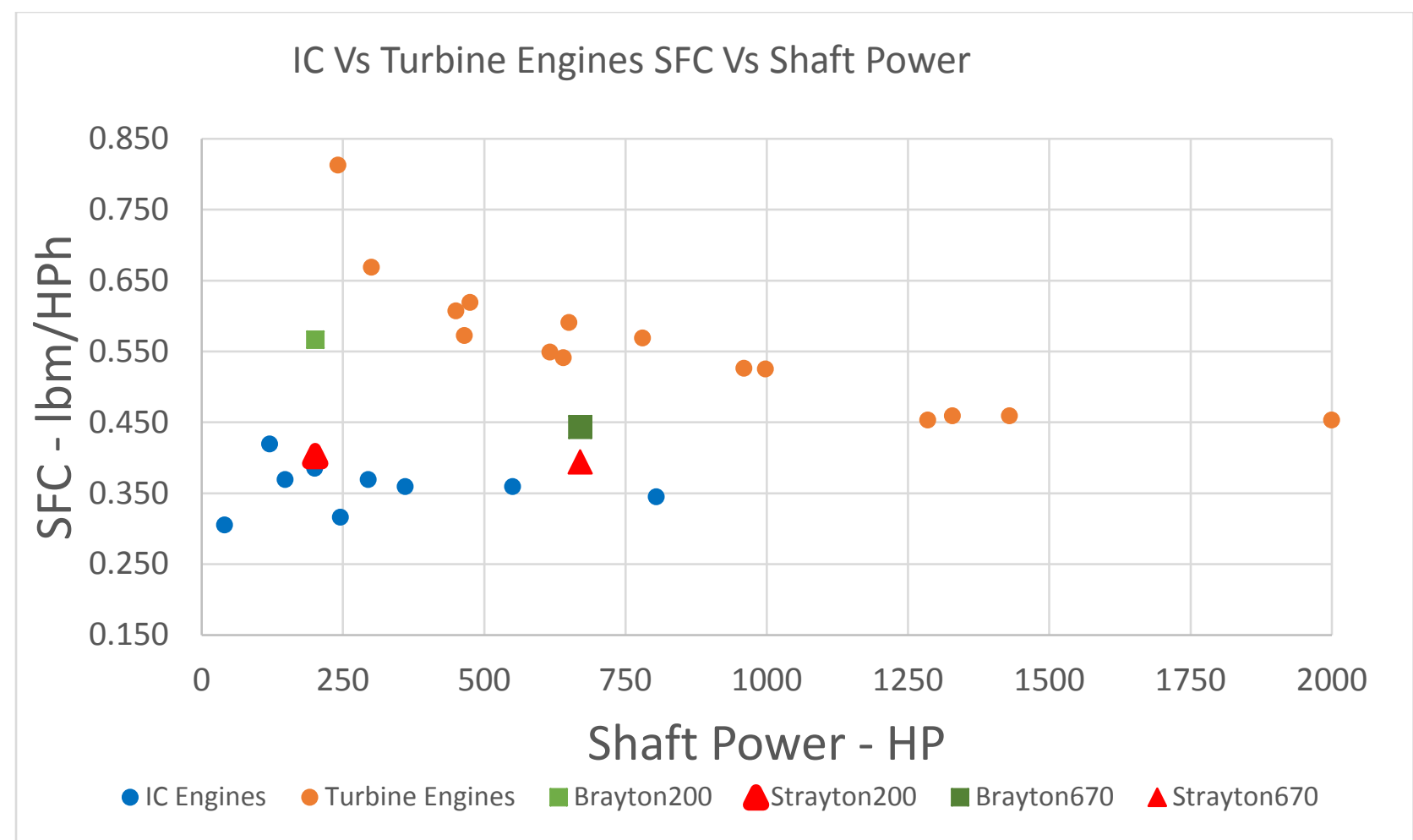

Figure 9: Strayton, IC, turbine engine SFC vs. shaft power. 


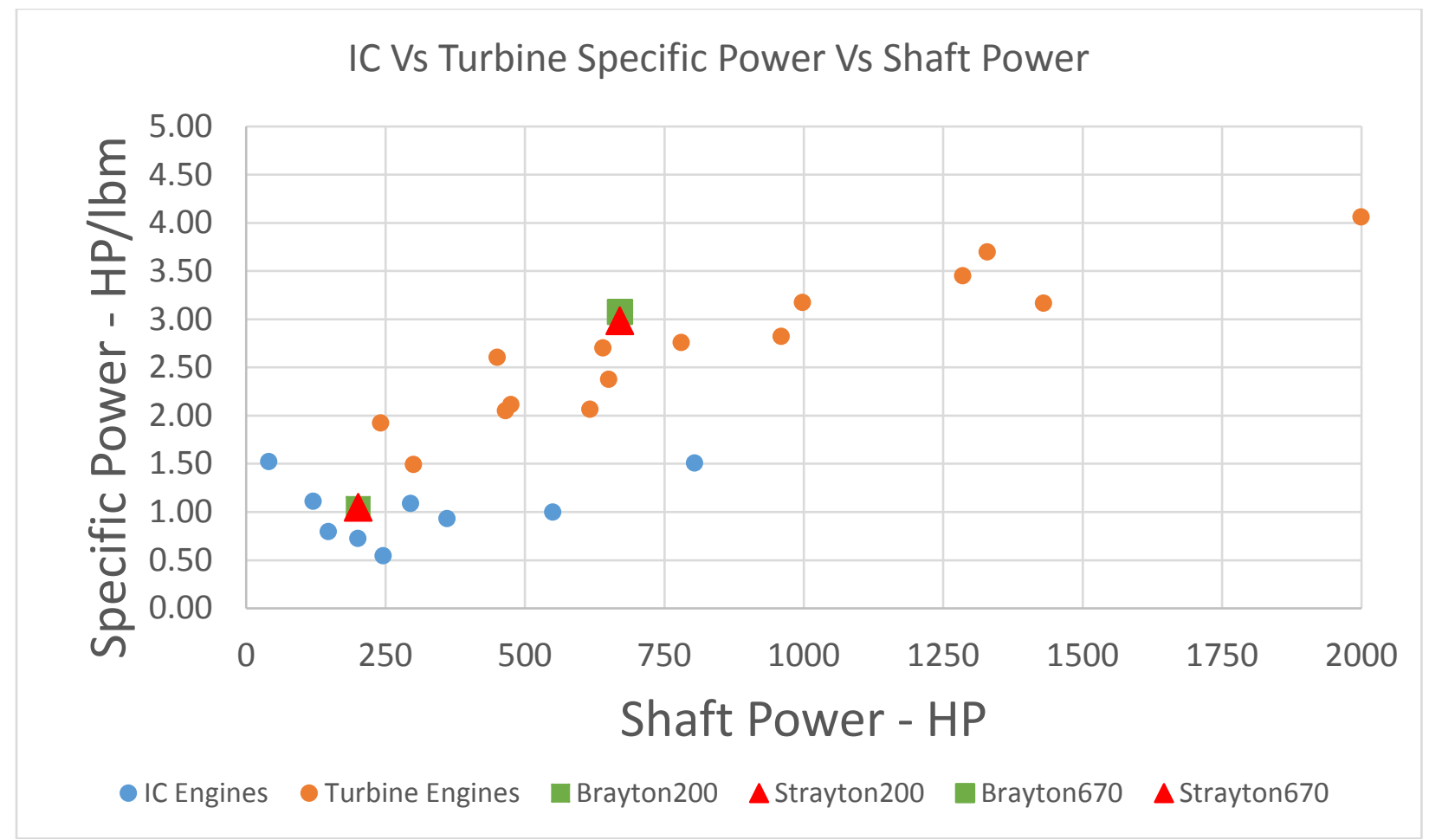

Figure 10: Strayton, IC, turbine engine specific power vs. shaft power.

\section{Strayton Engine Control Study}

An initial study was conducted to investigate control requirements for "off-design" variations in Strayton engine power output. This is reflective of the range in propulsive power exhibited as an aircraft transitions through different phases of flight such as takeoff, climb, cruise, and descent. The two primary control actuators of the Strayton engine are fuel flow supplied to the Brayton cycle and input power supplied to the Stirling cycle. An increase in fuel flow will result in increased Brayton cycle rotational speed, shaft power output, OPR, and operating temperatures. An increase in Stirling input power will increase Stirling output power along with the stroke length of the Stirling's compression (cold section) and expansion (hot section) pistons, and the $\dot{Q}_{C}$ and $\dot{Q}_{H}$ heat transfer rates between the two cycles. Adjustments to the total power output produced by the Strayton can be made by changing either fuel flow or Stirling power input. However, instead of making these adjustments in an ad hoc or independent manner, it is important to keep in mind that there are additional factors beyond total power output that should be considered. This includes striving to maintain maximum efficiency while also ensuring that no system operating limits are violated. To investigate this issue, a Stirling engine cycle was created using the Ohio University SEA software, which is coded in MATLAB.[11] An illustration of the design parameters considered in sizing the Stirling model are shown in Figure 11. This included swept and clearance volumes in the compression and expansion cylinder spaces, sizing of the cooler, heater, and regenerator components, specification of the working fluid gas type and mean pressure, and oscillation frequency of the design. These parameters were selected to match output power and efficiency of the Stirling Carnot cycle included in the baseline 200 HP NPSS Strayton engine model while operating at the SLS 1.4 TR design point specified in Table 2.

Once the Stirling cycle model was designed, it permitted analysis of the effects of changes in the Stirling's supply temperatures $\left(\mathrm{T}_{\mathrm{st}, \mathrm{H}}\right.$ and $\left.\mathrm{T}_{\mathrm{st}, \mathrm{C}}\right)$ and piston stroke length. Piston stroke length variations were simulated by adjusting the swept and clearance volumes of the model's compression and expansion cylinders. Given the SEA-based Stirling cycle model and the baseline NPSS-based Strayton cycle model described earlier, an evaluation was conducted to assess how overall Strayton cycle performance varied due to combined changes in Brayton fuel flow and Stirling piston stroke length. First, Strayton system efficiency and power output was assessed by varying the temperature ratio while holding piston stroke length at its $100 \%$ design point. This entailed an iterative process, where adjustments were made to the SEA and NPSS model inputs until matching between the $\mathrm{T}_{\mathrm{st}, \mathrm{H}}$ and $\mathrm{T}_{\mathrm{st}, \mathrm{C}}$ temperatures and the $\dot{Q}_{C}$ and $\dot{Q}_{H}$ heat transfer rates of both models were in agreement. This process was then repeated for different SEA Stirling model 
stroke lengths ranging from 95\% to $70 \%$ of full stroke. The results of this analysis are illustrated in Figure 12, which shows Strayton Efficiency vs. Power Output for various Stirling stroke lengths. Here, the solid red line denotes the turbine blade temperature limit of $2750^{\circ} \mathrm{R}$ while the dashed blue line shows the operating line that will provide optimal efficiency while adhering to the turbine blade temperature limit as power output is reduced from 200 to 100 horsepower. This figure shows that engine efficiency does not immediately decrease as power demand is reduced, and actually shows an efficiency increase for a range of the power settings. These results also confirm the inherent coupling between Brayton and Stirling cycles, and the need for coordinated control of them. Such information will be required for the development of integrated control schedules of Brayton (fuel flow) and Stirling (stroke length) operation over the range of operating conditions and power levels that a Strayton engine is designed for.

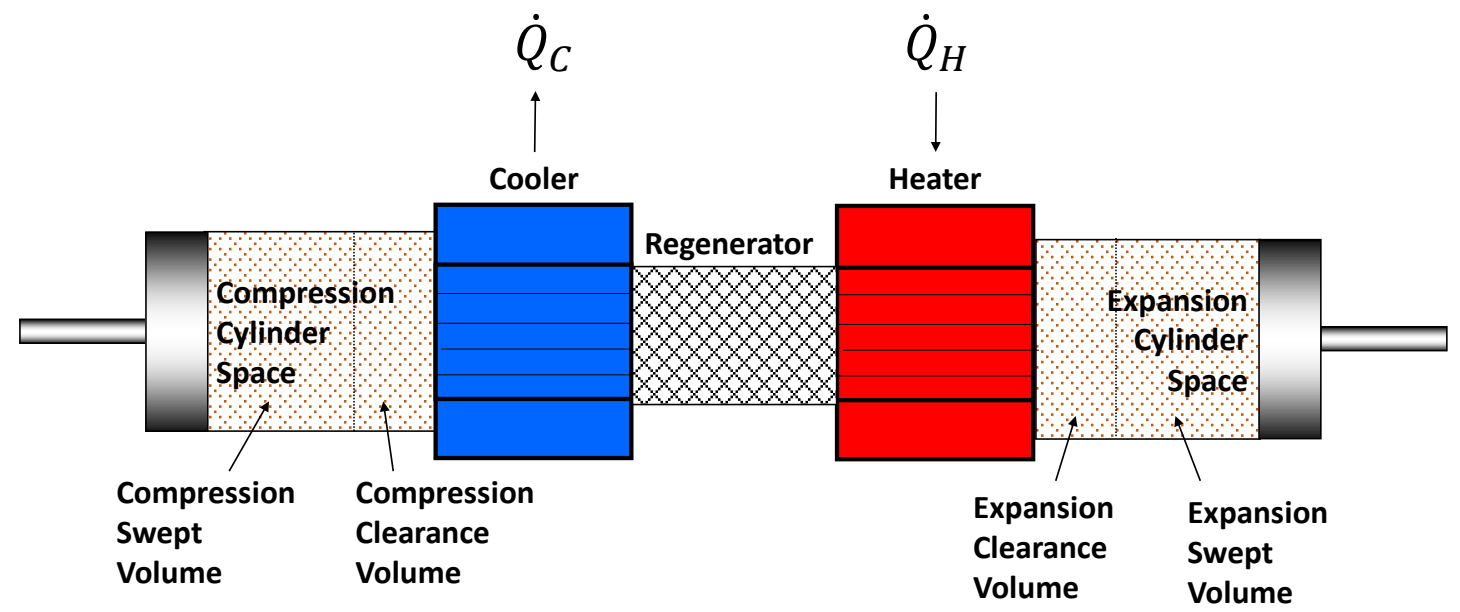

Figure 11: Stirling engine model design parameters. 


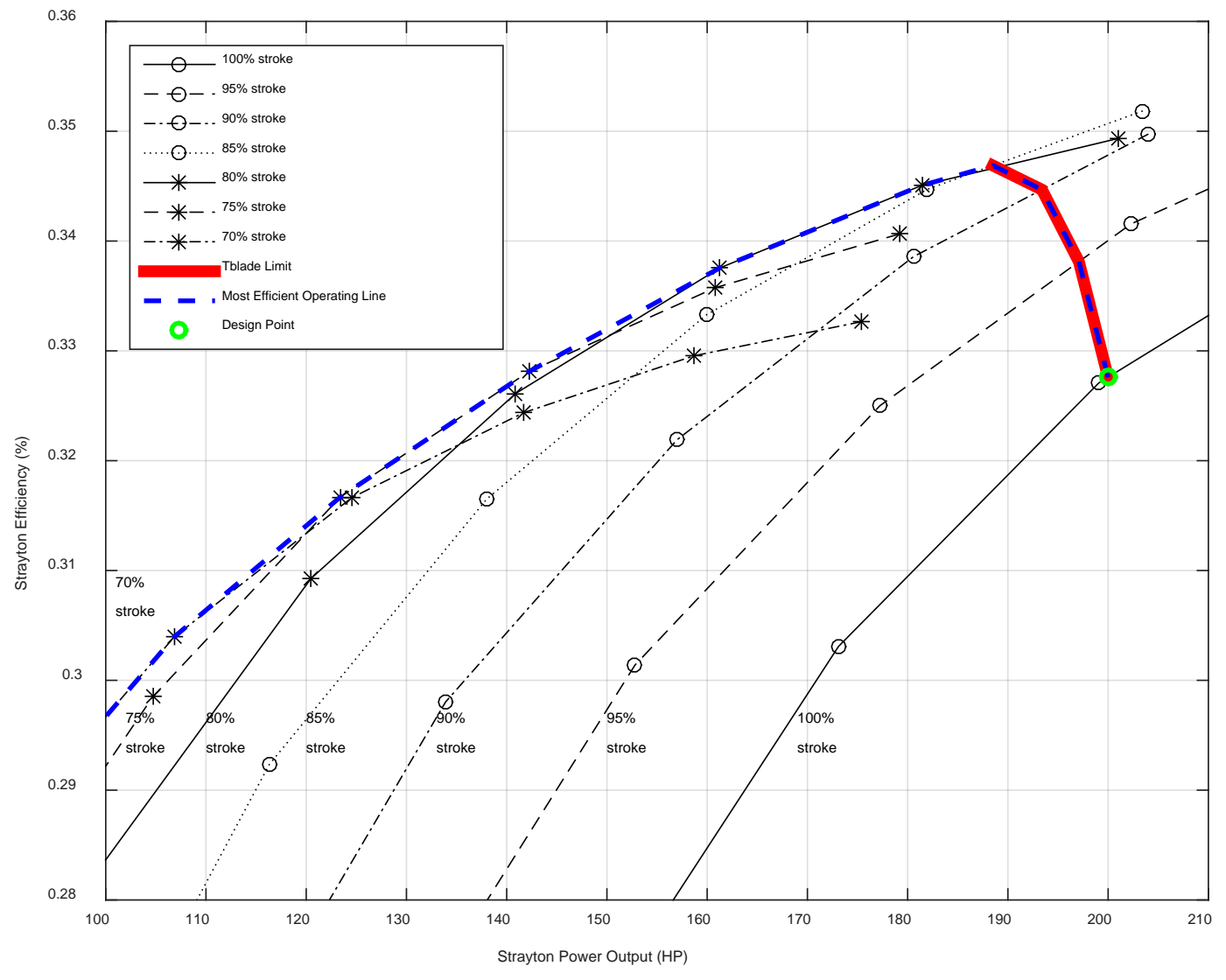

Figure 12: Strayton Engine Efficiency vs. Power Output for Various Stirling Stroke Lengths.

\section{Key Technologies and Challenges}

In the development of a competitive Strayton engine, certain technologies must be developed and challenges overcome. Work on these technologies could offer benefit to not only the creation of a Strayton engine, but would have uses in other applications. Drivers of the success of the Stayton engine essentially comes to 4 different technologies and research areas: high temperature materials and system operation, high power Stirling engines, convective blade cooling, and advanced control strategies.

In the results section of this paper it was shown that system efficiency gains for the Strayton are better than those of a typical Brayton cycle engine with increasing temperature. For this study it was assumed that acceptable liner temperature and blade temperature were in the range of 3200 and $2750{ }^{\circ} \mathrm{R}$, respectively. These assumed temperature are similar to those observed on larger gas turbine engines, however smaller engines tend to operate with a closer to $2000{ }^{\circ} \mathrm{R}$ limit due to cost issues. As newer lower cost material types that can withstand higher temperatures become available it is expected that these temperatures will increase. Research in high temperature ceramic materials shows promise with next-generation ceramic matrix composites expected to reach roughly $3200{ }^{\circ} \mathrm{R}$ and with the addition of environmental barrier coatings, this max temperature could reach $3500^{\circ}$ R.[17] For the Strayton these higher temperature materials should be considered due to the added advantage of higher temperature operation.

The development of reliable, small scale, highly efficient Stirling engines will be critical for enabling the Strayton engine concept. Conventional aircraft engine turbomachinery is expected to run for thousands of hours without major overhaul [18]. In order to be practical for aviation purposes, Stirling designs must provide comparable levels of reliability. Additionally, Stirling designs that support line replaceable unit (LRU) access and removal will be desirable. The design of highly efficient Stirling cycles will also be a key challenge. Past efforts have applied optimization methods for Stirling cycle design [19] as well as novel cycle enhancements such as 
cascaded stage designs to increase overall power output [20]. However, for Strayton applications the Stirling cycle design challenge is compounded by installation constraints. The Stirling design must fit within the volume of the Brayton shaft and the location of its components must properly align with the axial location of the hot (turbine) and cold (compressor exit) heat sources of the Brayton cycle. These factors should be considered when designing both the Brayton and Stirling cycles of the Strayton engine concept.

As temperatures within the engine core stream get hotter the cooling effect on turbine blades becomes more important. Figure 13 shows the temperature at various locations within the Strayton versus the hot side Stirling energy transfer. In this figure it may be observed that as energy transfer increases the difference between $\mathrm{T}_{4}$ and T_blade increases causing a blade cooling effect. Essentially, this cooling effect is caused by the creation of a heat transfer circuit and the drop in temperature of the blade surface is dictated by the difference in heat transfer speed between the core flow convection and blade material conduction or, in cases with heat pipes, the pipe heat transfer speed. This cooling effect is between 250 and $500{ }^{\circ} \mathrm{R}$, which is roughly half of what a convectional cooling flow might be expected to provide, given cooling flow from station 3 at $980{ }^{\circ} \mathrm{R}$ and an assumption of $50 \%$ blade film cooling efficiency.[21] However, it is known that with small engines these film cooling efficiencies may not be met due to physical restrictions on cooling flow passage creation.[22] In such cases where cooling flow is impossible or with the use of higher temperature materials that do not require such a substantial amount of cooling, Stirling engine blade cooling techniques may be explored.

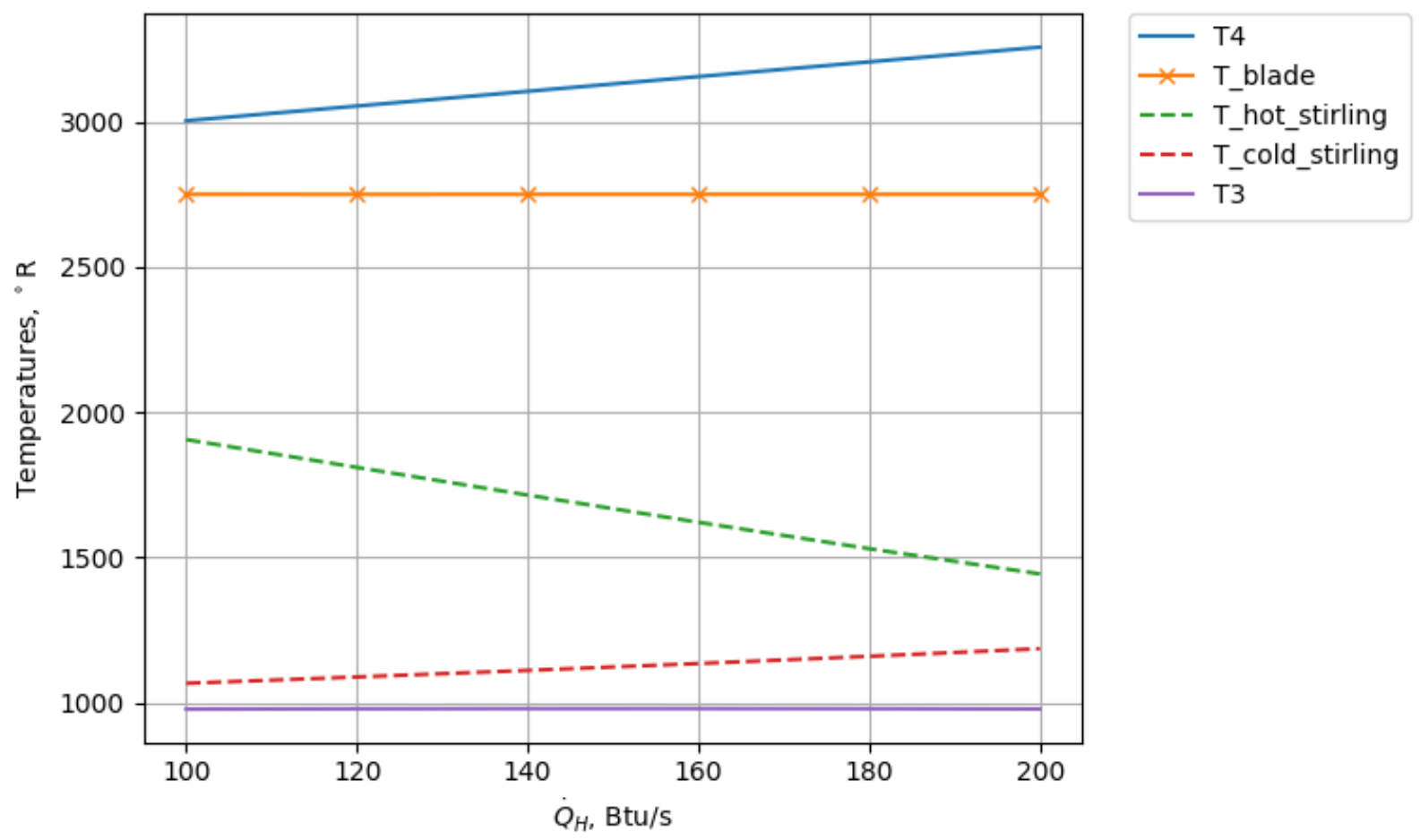

Figure 13: Strayton temperature profiles vs. Stirling hot side energy transfer.

Another major obstacle for this technology to overcome will be safety of the heat pipes used to increase heat transfer through the turbomachinery components. In order to operate at these elevated temperatures, the only working fluids with a high technology readiness level would be liquid alkali metals. This could pose a significant safety concern in the event of a system failure. In order to alleviate this concern, nonconventional fluids need to be characterized and investigated. This could include molten salts, exotic nanofluids, or other non-volatile liquid metal alloys. Fluids which could exist in a multiphase (liquid and gas) state at both the compressor exit and turbine inlet temperature are desirable in order to avoid a lengthy startup process.

Results presented in the Strayton engine control study section demonstrated the need for coordinated operation of the Brayton and Stirling cycles during off-design operation. Such control-based scheduling of the two cycles is 
necessary in order to achieve optimal efficiency while ensuring that all system operating limits are maintained as power demands vary. Similar types of analyses will be necessary to ensure optimal system-level performance for any new Strayton engine designs. It is also important to note that the controls analysis presented in this paper is a relatively simple steady-state analysis that only considered engine performance at fixed operating points. In actual applications, engine operation could be highly dynamic including rapid variations in demanded power output levels. Dynamic operation complicates the control design challenges associated with the Strayton engine, especially considering that the heat transfer capabilities of the Stirling may be slower than the dynamic response that the Brayton cycle is capable of. This becomes a particularly important consideration given the Stirling's role in providing Brayton turbine blade cooling. Dynamic control design and analysis is needed to ensure that the design is capable of providing the necessary power output responsiveness while simultaneously supplying adequate turbine blade cooling during any engine transients.

\section{Conclusions}

The Strayton Engine offers a concept that combines a Brayton cycle engine with a Stirling engine, where the Stirling engine is being used as another power generating engine, a recouperator for the Brayton cycle engine, and as a turbine blade cooling mechanism. Cycle analysis of the hybrid concept shows significant efficiency gain over a Brayton only cycle engine, with increasing gains as maximum temperature is increased. These gains were generally higher as overall power production was reduced because maximum Stirling power production is based on the temperature ratio of the system that is based on material choice, which does not scale with Brayton power increases. Additionally, a control study demonstrates the capability of the engine to hold efficiency gains during low power operation. Key technologies for this design include: high temperature materials to enable higher temperature operation, heat pipes for enabling heat transfer from to and from the Stirling engine, heat transfer enabling geometries to enable higher efficiency heat transfer through components, and higher power Stirling engines. Weight of adding the Stirling is generally offset with the reduction of Brayton cycle size that comes with generating a portion of the power with the Stirling. Turbine blade cooling can reduce turbine temperature significantly. Other positive considerations with the Strayton engine include; lower life cycle cost (compared with IC), lower emission profile (compared with IC), reduced vibration (compared with IC), and engine redundancy. The main negative considerations is an increased complexity.

\section{Acknowledgments}

The authors would like to thank the NASA Convergent Aeronautics Solutions (CAS) project, under the Transformative Aeronautics Concepts Program (TACP) for the funding of this work. Additionally, the authors would like to thank Rodger Dyson, Ralph Jansen, Gerald Welch, and James Felder of NASA Glenn Research Center for their support and advice on this task. 


\section{References}

[1] Duffy, M.J., Wakayama, S., Hupp, R., Lacy, R., Stauffer, M., “A Study in Reducing the Cost of Vertical Flight with Electric Propulsion,” $17^{\text {th }}$ AIAA Aviation Technology, Integration, and Operations Conference, AIAA 2017-3442, Denver, CO, Jun. 5-9, 2017.

[2] Jansen, R.H., Bowman,C., Jankovsky, A., Dyson, R., and Felder, J., “Overview of NASA Electrified Aircraft Propulsion Research for Large Subsonic Transports," 53rd AIAA/SAE/ASEE Joint Propulsion Conference, AIAA Propulsion and Energy Forum, AIAA 2017-4701, Atlanta, GA, 10-12 July, 2017.

[3] Johnson, W., Silva, C., Solis, E., “Concept Vehicles for VTOL Air Taxi Operations,” AHS Technical Conference on Aeromechanics Design for Transformative Vertical Flight, San Francisco, CA, Jan. 16-19, 2018.

[4] Silva, C., Johnson, W., Antcliff, K.R., Patterson, M.D.,“ VTOL Urban Air Mobility Concept Vehicles for Technology

Development,” AIAA Aviation Technology, Integration, and Operations Conference, AIAA 2018-3847, Atlanta, GA, 25-29 June, 2018.

[5] Snyder, C.A., "Personal Rotorcraft Design and Performance with Electric Hybridization,” 73을 American Helicopter Society (AHS) Annual Forum, Fort Worth, TX, 9-11 May, 2017.

[6] Thimsen, D., "Stirling Engine Assessment,” Electric Power Research Institute, 1007317,Final Report, October, 2002.

[7] Smirnov, D., Golkar, A., “Stirling Engine Systems Tradespace Exploration Framework,” Conference on System Engineering Research, Procedia Computer Science 44, 558-567, 2015.

[8] Dyson, R.W., "Novel Thermal Energy Conversion Technologies for Advanced Electric Air Vehicles,” AIAA Propulsion and Energy Forum, AIAA 2018-4993, Cincinnati, Oh, 9-11 July, 2018.

[9] Jones, S.M., "An Introduction to Thermodynamic Performance Analysis of Aircraft Gas Turbine Engine Cycles Using the Numerical Propulsion System Simulation Code," NASA Center for Aerospace Information, Hanover, MD, Cleveland, Ohio, 2007. [10] Walker, G., Stirling Engines, Oxford University Press, New York, 1980.

[11] Urieli, I., “Stirling Engine Machine Analysis”, Ohio University, URL: https://www.ohio.edu/mechanical/stirling/ [cited 30 Jan. 2019].

[12] Benvenuto, G., Farina, F., “The Use of Stirling Engines in Combined Cycle Power Plants”, IEEE Proceedings of the 24 ${ }^{\text {th }}$ Intersociety Energy Conversion Engineering Conference, Washington D.C., 6-11 Aug., 1989.

[13] Toro, C., Lior, N., "Analysis and Comparison of Solar-Heat Driven Stirling, Brayton and Rankine Cycles for Space Power Generation", Energy, Vol. 120, Feb. 2018, pp. 549-564

[14] Entezari, A., Manizadeh, A., Ahmadi, R., "Energetical, exergetical and economical optimization analysis of combined power generation system of gas turbine and Stirling engine", Energy Conversion and Management, Vol. 159, March 2018, pp. 189-203

[15] Chapman, J.W., "Multipoint Design and Optimization of a Turboshaft Engine for a Tiltwing Turboelectric Vertical Takeoff and Landing Air Taxi”, AIAA Science and Technology Forum (SciTech), AIAA 2019-1948, San Diego, CA, 7-11 January, 2019. [16] Bejan, A. “Convection Heat Transfer”, $4^{\text {th }}$ Edition, Hoboken, NJ, 2013.

[17] Lee, K.N., Roode, M.V., "Environmental barrier coatings enhance performance of SiC/SiC ceramic matrix composites”, American Ceramic Society Bulletin, Vol. 98, No. 3, March, 2015.

[18] Mattingly, J.D., Heiser, W.H., Pratt, D.T., Aircraft Engine Design, American Institute of Aeronautics, Inc, ${ }^{\text {nd }}$ Edition, Virginia 2002.

[19] Toghyani, S., Kasaeian, A., Ahmadi, M.H., "Multi-Objective Optimization of Stirling Engine using Non-ideal Adiabatic Method,” Energy Conversion and Management, Vol. 80, April 2014, Pages 54-62.

[20] Gardner, D.L., Swift, G.W., “A Cascade Thermoacoustic Engine,” Journal of the Acoustical Society of America Vol. 114, No. 4, October 2003.

[21] Krypros, J.A., Melcher, K.J., “A reduced Model for Prediction of Thermal and Rotational Effects on Turbine Tip Clearance,” NASA/TM-2003-212226.

[22] Lyes, R.A., The history of North American small gas turbine aircraft engines, American Institute of Aeronautics and Astronautics, Inc. (AIAA), Reston VA, 1999. 